\title{
Association study between ZFHX3 gene polymorphisms and obesity in Korean population
}

\author{
Seung-Ae Yang* \\ College of Nursing, Sungshin Women's University, Seoul, Korea
}

The aim of this study is to investigate whether single nucleotide polymorphisms (SNPs) of zinc finger homeobox 3 (ZFHX3) gene are susceptibility to obesity. Recently, several study suggested that specific polymorphisms in various genes may have effect to obesity. In present study, 54 SNPs of ZFHX3 gene were genotyped in 209 overweight and obese patients with a body mass index (BMI) $\geq 23 \mathrm{~kg} / \mathrm{m}^{2}$ (mean \pm standard deviation, $44.7 \pm 6.4 \mathrm{~kg} / \mathrm{m}^{2}$ ) and 159 healthy controls with a BMI of $18.5-23.0 \mathrm{~kg} / \mathrm{m}^{2}\left(43.6 \pm 6.2 \mathrm{~kg} / \mathrm{m}^{2}\right)$. Genotyping of each SNP was performed by custom DNA chip. Logistic regression models (dominant, recessive, and log-additive models) were used to calculate odds ratio,
$95 \%$ confidence interval, and $P$-values. Significant association was considered at $P<0.05$. Among tested SNPs in ZFHX3 genes, seven SNPs of ZFHX3 gene showed significant association with obesity $(P<0.05$ in each model, respectively). In conclusion, these results indicate that SNPs of ZFHX3 gene might be contributed to development of obesity in the Korean population.

Keywords: Overweight, Obese, Obesity, ZFHX3, Single nucleotide polymorphism

\section{INTRODUCTION}

Previous study observed that the zinc finger homeobox 3 (ZFHX3) gene was isolated and reported (Morinaga et al., 1991), as to be encoding a protein which works as enhancer to human alpha-fetoprotein $(A F P)$ gene. It was proposed that ZFHX3 binds to AT-rich motif in human AFP gene region, and it has 17 zinc finger motifs with large size of $306 \mathrm{kDa}$ (Morinaga et al., 1991). $A F P$ is considered as fetal gene which related to albumin, and its level rapidly declines by first 2 years of life (Schieving et al., 2014). Additionally, AFP gene is a famous marker of cancer in adult (Schieving et al., 2014; Staples, 1986).

However, Dong et al. (2010) proposed that ZFHX3 (which was shown as ATBF1) has an ATPase A-motif, two DEAH box-like sequences, and 23 zinc finger motifs with lengths of 3703 amino acids. They suggested that ZFHX3 may have a role in inhibition of estrogen receptor (ER)-mediated gene transcription and proliferation of breast cancer cells (Dong et al., 2010). Moreover, somat- ic gene mutation of ZFHX3 may also affect prostate cancer risk (Xu et al., 2006), and it was also involved in cell proliferation of prostate cancer (Sun et al., 2005). Breast cancer and prostate cancer are closely related diseases with obesity (Engin, 2017).

A recent study performed in Chinese population shows that level of serum AFP in metabolic syndrome were significantly higher (Chen et al., 2016), although the AFP level was not directly associated with central obesity alone in their result (Chen et al., 2016). However, increased serum AFP level was coexisted with fatty liver (Xu et al., 2014). Plus, there have been many studies presenting the relationship between ER and obesity, or adipocyte responses (Luglio, 2014; Miao et al., 2016; Pedram et al., 2016; Strong et al., 2015; Zhu et al., 2016). Therefore, it might be observed that those previous studies suggest the possible relationship, between the level of ZFHX3 and obesity.

In the genetic control of expressions, it has been suggested that intronic single nucleotide polymorphisms may be associated with protein levels, because there are parts of nucleotides which may
*Corresponding author: Seung-Ae Yang (iD https://orcid.org/0000-0002-6235-2752 College of Nursing, Sungshin Women's University, 55 Dobong-ro 76ga-gil, Gangbuk-gu, Seoul 01133, Korea

Tel: +82-2-920-7728, Fax: +82-2-968-0560, E-mail: ewha63@sungshin.ac.kr Received: July 11, 2017 / Accepted: August 12, 2017
This is an Open Access article distributed under the terms of the Creative Commons Attribution Non-Commercial License (http://creativecommons.org/licenses/by-nc/4.0/) which permits unrestricted non-commercial use, distribution, and reproduction in any medium, provided the original work is properly cited. 
serve as regulatory elements (Barrett et al., 2012), and which may also affect transcription as intron-mediated enhancement (Shaul, 2017). Cis-acting regulatory elements may affect expression levels of transcripts (Martin et al., 2014; Sadee, 2009). Furthermore, recent studies report novel mechanisms of noncoding RNA regulating cellular functions, such as circular RNAs (Hsiao et al., 2017) and heterochromatins (Shimada et al., 2016).

However, up to now, there was no previous study performing direct analysis of whether association between SNPs of ZFHX3 gene and obesity. Therefore, we investigated the SNPs of ZFHX3 gene in the groups of normal and obese individuals in Korean population.

\section{MATERIALS AND METHODS}

\section{Study subjects}

In the present study, 209 overweight/obese subjects and 159 controls were recruited. These subjects were recruited among participants that examined a general health check-up program. Subjects with severe diseases such as stroke, psychiatric disorders, and cancers were excluded. The biochemical characteristics of individuals were measured such as fasting plasma glucose, fasted glycated hemoglobin, total cholesterol. Body mass index (BMI) is calculated as weight $(\mathrm{kg})$ divided by the square of height $(\mathrm{m})$. According to the classification of Korean Society for the Study of Obesity (underweight, $\mathrm{BMI}<18 \mathrm{~kg} / \mathrm{m}^{2}$; normal, BMI 18 to $<23 \mathrm{~kg} / \mathrm{m}^{2}$; moderately obese, BMI 23 to $<25 \mathrm{~kg} / \mathrm{m}^{2}$; obesity I, BMI 25 to $<30 \mathrm{~kg} / \mathrm{m}^{2}$; obesity II, BMI $\geq 30 \mathrm{~kg} / \mathrm{m}^{2}$ ), subjects were divided into two subgroups, the abnormal (overweight/obese) group (BMI $\left.\geq 23 \mathrm{~kg} / \mathrm{m}^{2}\right)$ and the normal group $\left(18 \mathrm{~kg} / \mathrm{m}^{2} \leq \mathrm{BMI}<23 \mathrm{~kg} / \mathrm{m}^{2}\right)$.

\section{SNP selection and genotyping}

Peripheral bloods of all subjects were collected in ethylenediamine tetraacetic acid or heparin tube. Genomic DNAs were extracted by QIAamp DNA mini kit (QIAGEN, Valencia, CA, USA). We selected 54 tagging SNPs in ZFHX3 gene. Genotype of each SNP was performed by custom DNA chip.

\section{Statistical analysis}

SNPStats (http://bioinfo.iconcologia.net/index.php) and IBM SPSS Statistics ver. 23.0 (IBM Co., Armonk, NY, USA) were used to determine the odds ratio (OR), 95\% confidence interval (CI), and $P$-value. Logistic regression models (dominant $[\mathrm{A} / \mathrm{A}$ genotype vs. $A / B$ genotype $+B / B$ genotype], recessive $[A / A$ genotype $+A / B$ genotype vs. $\mathrm{B} / \mathrm{B}$ genotype], and log-additive models [A/A geno- type vs. A/B genotype vs. B/B genotype]) were applied. The $P$-value below 0.05 was considered significant.

\section{RESULTS}

In order to evaluate the association between ZFHX3 gene and susceptibility of obesity, we genotyped and analyzed the 54 SNPs of $Z F H X 3$ gene. In genotypic analysis, we observed that the seven SNPs (rs4788480, rs8055870, rs1010852, rs16971447, rs 9930445, rs4788489, and rs879324) were associated with susceptibility of obesity $(P<0.05$ in each SNP). In the control group, the genotype distributions for seven SNPs (rs4788480, rs8055870, rs1010852, rs16971447, rs9930445, rs4788489, and rs879324) were in Hardy-Weinberg equilibrium (rs4788480, $P=0.058$; rs8055870, $P=0.51$; rs1010852, $P=0.16$; rs16971447, $P=1.00$; rs9930445, $P=0.34$; rs4788489, $P=0.10$; and rs879324, $P=$ 0.86 , data not shown).

The genotype frequencies of the polymorphisms were compared between the control group and the overweight/obese group by using logistic regression model (dominant, recessive, and log-additive models). Among significant SNPs (rs4788480, rs8055870, rs1010852, rs16971447, rs9930445, rs4788489, and rs879324), minor allele of five SNPs (rs4788480, rs8055870, rs16971447, rs9930445, and rs879324) showed protective factor in susceptibility of obesity and minor alleles of two SNPs (rs1010852 and rs4788489) showed risk factor in present results.

The five SNPs showed association with obesity in each model (rs4788480: OR, 0.62; 95\% CI, 0.41-0.95, $P=0.260$ in dominant model; rs8055870: OR, 0.64; 95\% CI, 0.42-0.98; $P=$ 0.0410 in dominant model; OR, 0.68; 95\% CI, 0.47-0.99; $P=0.440$ in log-additive model; rs16971447: OR, 0.58; $95 \% \mathrm{CI}$, 0.38-0.89; $P=0.0110$ in dominant model; OR, 0.68; $95 \% \mathrm{CI}$, $0.50-0.93 ; P=0.0130$ in log-additive model; rs9930445: OR, 0.52 ; 95\% CI, 0.33-0.82; $P=0.0041$ in dominant model; OR, $0.72 ; 95 \% \mathrm{CI}, 0.54-0.97 ; P=0.030$ in log-additive model; and rs879324: OR, 0.70; 95\% CI, 0.50-0.97; $P=0.0320$ in log-additive model).

And two SNPs (rs1010852 and rs4788489) also showed association with obesity (rs1010852: OR, 2.19; 95\% CI, 1.16-4.13; $P=0.012$ in recessive model and rs4788489: OR, $1.93 ; 95 \% \mathrm{CI}$, $1.17-3.18 ; P=0.0083$ in recessive model; OR, $1.49 ; 95 \% \mathrm{CI}$, $1.49 ; 95 \% \mathrm{CI}, 1.11-1.99 ; P=0.0068$ in log-additive model).

However, other SNPs did show any significant association with susceptibility of obesity. In haplotype analysis, we analyzed haplotype in significant SNPs (rs4788480, rs8055870, rs1010852, 
rs16971447, rs9930445, rs4788489, and rs879324) using Haploview 4.2. There were four haplotypes in one LD block consisted of rs16971447, rs9930445, and rs4788489 (TTT, CCG, TCG, and TTG haplotype) in ZFHX3 gene. Among four haplotypes, frequencies TTT haplotype and CCG in ZFHX3 gene between the control group and the overweight/obese group showed significant difference (TTT haplotype, $P=0.0119$ and CCG haplotype, $P=0.0173)$.

\section{DISCUSSION}

ZFHX3 gene is located on chromosome 16, $\mathrm{q}$ arm position 22.2-22.3 (http://www.ncbi.nlm.nih.gov/gene/463). The chromosomal position is frequently associated with deletion in various cancer patients.

ZFHX3 was regarded as AFP enhancer, however, recent studies of $\mathrm{ZFHX} 3$ report its association to heart diseases. Interestingly, chromosome 16q22 was also associated with cardiovascular phenotypes. Several studies demonstrated that ZFHX3 SNP were significantly associated with ZFHX3 expression, which is in transcript-specific manner, regarding each of ZFHX3 isoforms, and they did not find variant associated to the expression (Hsiao et al., 2017). CAA repeat polymorphisms in exon 9 of the $Z F H X 3$ gene was related to coronary heart disease in Chinese population, that 10 repeat allele was significantly associated with hypertension, diabetes, or dyslipidemia. There were also 9 or 11 repeats of CAA, however, rare alleles (Sun et al., 2015).

Zhai et al. (2015) found that rs 7193343 may affect atrial fibrillation (AF) in Caucasians population, however it was not associated in Asian population (Zhai et al., 2015). In another study in Chinese population, rs2106261 and rs6499600 were significantly associated, and rs16971436 was borderline associated with AF (Liu et al., 2014). Liu et al. (2014) hypothetically suggested that ZFHX3 expression change may vary STAT3 regulation to result susceptibility to AF.

In addition, in the National Center for Biotechnology Information phenotype-genotype integrator (PheGenI) of ZFHX3 SNPs (https:// www.ncbi.nlm.nih.gov/gap/phegeni?tab = 1\&gene = 463), rs1548374 was associated with waist circumference, obesity, and BMI.

In our study result, seven SNPs of ZFHX3 gene (rs4788480, rs8055870, rs1010852, rs16971447, rs9930445, rs4788489, and rs879324) were associated with obesity. However, PheGenI obesity SNP rs1548374 was not associated in our result,

Our study has some limitations, that only a small Korean population was analyzed, whole variants near the ZFHX3 gene were not assessed, and actual expression in the individuals were not measured. Furthermore, ZFHX3 expression study will be needed in the adipocytes in the future studies. However, our study may partly agree with previous results that $Z F H X 3$ variants may significantly affect phenotypic occurrence, and such disease phenotypes are in closely related spectrum to obesity.

In conclusion, we suggest that polymorphisms of $Z F H X 3$ gene (rs4788480, rs8055870, rs1010852, rs16971447, rs9930445, rs4788489, and rs879324) may be contributed to susceptibility of obesity in Korean population.

\section{CONFLICT OF INTEREST}

No potential conflict of interest relevant to this article was reported.

\section{REFERENCES}

Barrett LW, Fletcher S, Wilton SD. Regulation of eukaryotic gene expression by the untranslated gene regions and other non-coding elements. Cell Mol Life Sci 2012;69:3613-3634.

Chen Y, Zhao Y, Feng L, Zhang J, Zhang J, Feng G. Association between alpha-fetoprotein and metabolic syndrome in a Chinese asymptomatic population: a cross-sectional study. Lipids Health Dis 2016;15:85.

Dong XY, Sun X, Guo P, Li Q, Sasahara M, Ishii Y, Dong JT. ATBF1 inhibits estrogen receptor (ER) function by selectively competing with AIB1 for binding to the ER in ER-positive breast cancer cells. J Biol Chem 2010;285:32801-32809.

Engin A. Obesity-associated breast cancer: analysis of risk factors. Adv Exp Med Biol 2017;960:571-606.

Hsiao KY, Sun HS, Tsai SJ. Circular RNA - New member of noncoding RNA with novel functions. Exp Biol Med (Maywood) 2017;242:11361141.

Liu Y, Ni B, Lin Y, Chen XG, Fang Z, Zhao L, Hu Z, Zhang F. Genetic polymorphisms in ZFHX3 are associated with atrial fibrillation in a Chinese Han population. PLoS One 2014;9:e101318.

Luglio HF. Estrogen and body weight regulation in women: the role of estrogen receptor alpha (ER- $\alpha$ ) on adipocyte lipolysis. Acta Med Indones 2014;46:333-338.

Martin RI, Owens WA, Cunnington MS, Mayosi BM, Koref MS, Keavney BD. Chromosome 16q22 variants in a region associated with cardiovascular phenotypes correlate with ZFHX3 expression in a transcript-specific manner. BMC Genet 2014;15:136.

Miao YF, Su W, Dai YB, Wu WF, Huang B, Barros RP, Nguyen H, Maneix L, Guan YF, Warner M, Gustafsson JÅ. An ER $\beta$ agonist induces 
browning of subcutaneous abdominal fat pad in obese female mice. Sci Rep 2016;6:38579.

Morinaga T, Yasuda H, Hashimoto T, Higashio K, Tamaoki T. A human alpha-fetoprotein enhancer-binding protein, ATBF1, contains four homeodomains and seventeen zinc fingers. Mol Cell Biol 1991;11: 6041-6049.

Pedram A, Razandi M, Blumberg B, Levin ER. Membrane and nuclear estrogen receptor $\alpha$ collaborate to suppress adipogenesis but not triglyceride content. FASEB J 2016;30:230-240.

Sadee W. Measuring cis-acting regulatory variants genome-wide: new insights into expression genetics and disease susceptibility. Genome Med 2009;1:116.

Schieving JH, de Vries M, van Vugt JM, Weemaes C, van Deuren M, Nicolai J, Wevers RA, Willemsen MA. Alpha-fetoprotein, a fascinating protein and biomarker in neurology. Eur J Paediatr Neurol 2014;18: 243-248.

Shaul O. How introns enhance gene expression. Int J Biochem Cell Biol 2017 Jul 1 [Epub]. pii: S1357-2725(17)30154-1. https://doi.org/10.1016/ j.biocel.2017.06.016.

Shimada Y, Mohn F, Bühler M. The RNA-induced transcriptional silencing complex targets chromatin exclusively via interacting with nascent transcripts. Genes Dev 2016;30:2571-2580.

Staples J. Alphafetoprotein, cancer, and benign conditions. Lancet 1986;2:1277.

Strong AL, Ohlstein JF, Biagas BA, Rhodes LV, Pei DT, Tucker HA, Lla- mas C, Bowles AC, Dutreil MF, Zhang S, Gimble JM, Burow ME, Bunnell BA. Leptin produced by obese adipose stromal/stem cells enhances proliferation and metastasis of estrogen receptor positive breast cancers. Breast Cancer Res 2015;17:112.

Sun S, Zhang W, Chen X, Song H. The CAA repeat polymorphism in the ZFHX3 gene is associated with risk of coronary heart disease in a Chinese population. Tohoku J Exp Med 2015;235:261-266.

Sun X, Frierson HF, Chen C, Li C, Ran Q, Otto KB, Cantarel BL, Vessella RL, Gao AC, Petros J, Miura Y, Simons JW, Dong JT. Frequent somatic mutations of the transcription factor ATBF1 in human prostate cancer. Nat Genet 2005;37:407-412.

Xu J, Sauvageot J, Ewing CM, Sun J, Liu W, Isaacs SD, Wiley KE, Diaz L, Zheng SL, Walsh PC, Isaacs WB. Germline ATBF1 mutations and prostate cancer risk. Prostate 2006;66:1082-1085.

Xu P, Xu CF, Wan XY, Yu CH, Shen C, Chen P, Xu GY, Li YM. Association between serum alpha-fetoprotein levels and fatty liver disease: a cross-sectional study. World J Gastroenterol 2014;20:11865-11870.

Zhai C, Cong H, Liu Y, Zhang Y, Liu X, Zhang H, Ren Z. Rs7193343 polymorphism in zinc finger homeobox 3 (ZFHX3) gene and atrial fibrillation: an updated meta-analysis of 10 case-control comparisons. BMC Cardiovasc Disord 2015;15:58.

Zhu Y, Shen J, Gao L, Feng Y. Estrogen promotes fat mass and obesity-associated protein nuclear localization and enhances endometrial cancer cell proliferation via the mTOR signaling pathway. Oncol Rep 2016; 35:2391-2397. 